\title{
Interactive comment on "Meteo and hydrodynamic data in the Mar Grande and Mar Piccolo by the LIC Survey, winter and summer 2015" by Michele Mossa et al.
}

\section{Stefano Sibilla (Referee) \\ stefano.sibilla@unipv.it}

Received and published: 4 November 2020

\section{General comments}

The paper describes the meteorologic and hydrodynamic datasets collected at two fixed stations located in the Mar Grande (MG) and in the Mar Piccolo (MP) bays of the Taranto harbour. Both stations are equipped with an ADCP profiler and a wave array; the first station is also equipped with a weather station and sensors of different water quality parameters. The stations allowed the Authors to collect, for a winter and a summer month in 2015 , current profile, wave, meteo and water quality data records at the MG station and current profile, wave and temperature data records at the MP 
station.

The provided datasets can be used to both complement and validate the findings of other studies and numerical models, in order to better understand the hydrodynamic and biological patterns which characterize this complex coastal basin. The good quality and completeness of these datasets can therefore highly contribute to transform the Mar Grande/Mar Piccolo case study in a benchmark case, upon which methods and models can be tested, before extending them to similar basins.

\section{Specific comments}

In the paper, the Authors show a sample of the results obtained from the MG station in terms of direction and intensity of surface and bottom currents, of winds and waves, as well as time series of temperature, salinity, dissolved oxygen and chlorophyll. A brief interpretation of these data, in terms of current circulation patterns and of water quality time trends, is also proposed.

The results obtained from the MP station are instead not shown and commented. I understand that this is probably due to conciseness reasons; however, a brief comment about the quality and use of these data may add value to the paper. In particular, the Authors may explain why the MP station is located in the navigable channel between the two bays and which are the advantages (or the limits, if any) of this location in terms of information given by the station on the circulation regimes in the Mar Piccolo and on the flows exchanged through the channel itself.

Interactive comment on Earth Syst. Sci. Data Discuss., https://doi.org/10.5194/essd-2020-229, 2020. 